semblages existing at this temperature are indicated by the triangles $L^{\prime \prime}-R^{\prime}-C, R-P^{\prime}-C$, and $R-O^{\prime}-P^{\prime}$.

Isothermal planes may be drawn for other temperatures, or alternate methods may be employed to show crystallization phenomena in this system. Figure 9, which shows a series of three phase boundaries, is an aid in following ternary crystallization paths, for compositions of crystalline phases in equilibrium with liquids on boundary curves are indicated. From Fig. 10 may be estimated compositions of two crystal- line phases in equilibrium just below solidus temperatures. For a metasilicate and orthosilicate solid solution in equilibrium, the orthosilicate phase has a higher $\mathrm{Mn}: \mathrm{Mg}$ ratio. In the equilibrium between an oxide and an orthosilicate solid solution, the oxide phase has the higher $\mathrm{Mn}: \mathrm{Mg}$ ratio.

\section{Acknowledgment}

This research was made possible through financial support of the Bethlehem Steel Company.

\title{
Microstructure of Silica in the Presence of Iron Oxide
}

\section{bY LAWRENCE H. VAN VLACK}

Department of Chemical and Metallurgical Engineering, University of Michigan, Ann Arbor, Michigan

\begin{abstract}
The microstructures that are developed when iron oxide reacts with excess silica at elevated temperatures are described. Compacts of powdered quartz and iron oxide were heated to various temperatures and under selected conditions of oxidation to determine the effect of these parameters on microstructure. The results show that temperature has a small but measurable effect on the geometry of the silica and liquid phases. The oxidation level does not have an effect on the geometry of the phases in this system other than to reduce the liquid content by introducing magnetite as a secondary phase. The strength of silica brick in the presence of high liquid contents probably arises from the interfacial-energy relations which maintain considerable solid-to-solid contact at elevated temperatures.
\end{abstract}

\section{Introduction}

F the high-temperature strengths of refractories are compared, one is impressed by the fact that silica brick maintain their strength in the presence of a liquid phase better than do magnesia brick. For example, a zone 2 in. behind the hot face of an open-hearth silica roof brick may contain as much as $25 \%$ impurities and $35 \%$ liquid. ${ }^{1}$ Even so, the brick will continue to support a load at service temperatures. In contrast, $2 \%$ silica in magnesia refractories can produce $4 \%$ liquid, a quantity which is sufficient to introduce cracks and failure in the subsurface zones of the brick during hightemperature service. ${ }^{2}$

Received November 18, 1958; revised copy received October 2. 1959 .

The writer is professor of engineering materials and metallurgy, Department of Chemical and Metallurgical Engineering, University of Michigan.

'R. G. Wells and L. H. Van Vlack, "Alteration of Silica Brick During Open Hearth Service"; unpublished data, South Works, United States Steel Corporation, 1950.

? R. G. Wells and L. H. Van Vlack, "Mineral and Chemical Changes in Periclase Brick under Conditions of Steel Plant Operation," J. Am. Ceram. Soc., 34 [2] 64-70 (1951).
A microscopic examination revealed a definite difference between the microstructures of these magnesia and silica base materials. The liquid in the magnesia brick formed a nearly complete film around the periclase grains. The liquid in the silica brick did not penetrate the grain interfaces; rather, there was still considerable solid-to-solid contact. The larger amount of liquid was located at the grain edges. These observations led to this study in which (1) time, (2) temperature, and (3) atmosphere were considered as possible variables affecting the microstructure and hence the strength characteristics of silica refractories.

\section{Previous Work}

Three areas of literature review were necessary for this work: (1) temperature studies, (2) oxidation studies, and (3) factors controlling microstructure.

\section{(1) Temperature Sfudies}

The phase relations for the system ferrous oxide-silica are well established. In the presence of excess silica, the $\mathrm{SiO}_{2}$ content of the liquidus increases from $38 \%$ for the eutectic liquid at $21500^{\circ} \mathrm{F}$. to $55 \%$ for the monotectic liquid at $3090^{\circ} \mathrm{F}^{3}$ Fayalite $\left(\mathrm{Fe}_{2} \mathrm{SiO}_{4}\right)$ is the secondary solid phase in the presence of excess silica.

Under equilibrium conditions, cristobalite is the primary phase between $1470^{\circ} \mathrm{C}$. $\left(2678^{\circ} \mathrm{F}\right.$.) and the melting temperature at $1710^{\circ} \mathrm{C} .\left(3110^{\circ} \mathrm{F}\right.$.). The stability range of tridymite is between $1470^{\circ}$ and $875^{\circ} \mathrm{C}$. $\left(1607^{\circ} \mathrm{F}\right.$.). It is well known, however, that cristobalite is found below $1470^{\circ} \mathrm{C}$. as a metastable phase.

\section{(2) Oxidation Studies}

The siliceous liquids in the system iron oxide-silica investigated by Bowen and Schairer ${ }^{3}$ contained ferrous oxide. More oxidizing conditions alter the phase relation somewhat. Darken's ${ }^{4}$ results are summarized in Fig. 1. This presentation is, in reality, a plot of the silica-rich binary eutectic troughs of the ternary system $\mathrm{FeO}-\mathrm{Fe}_{2} \mathrm{O}_{3}-\mathrm{SiO}_{2}$ as a function

${ }^{3}$ N. L. Bowen and J. F. Schairer, "The System $\mathrm{FeO}-\mathrm{SiO}_{2}$," Am. J. Sci., [5th Series], 24 [141] 177-213 (1932); Ceram. Abstr., 12 [2] 83 (1933).

4 L. S. Darken, "Melting Points of Iron Oxides on SilicaPhase Equilibria in the System Fe-Si-O as a Function of Gas Composition and Temperature," J. Am. Chem. Soc., 70 [6] 2046-53 (1948); Ceram. Abstr., 1949, February, p. $64 h$. 


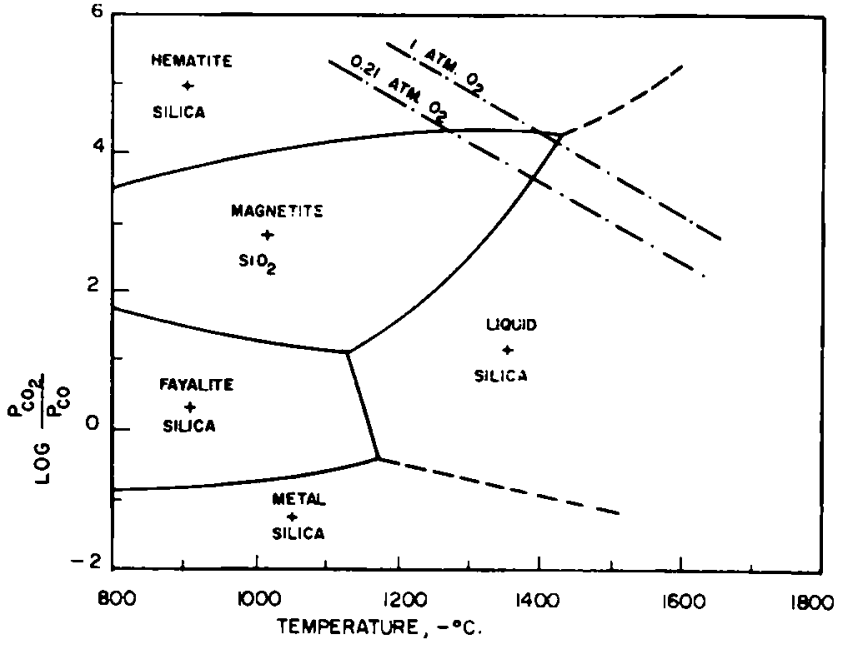

Fig. 1. Iron oxide-silica phoses vs, oxidation level lafter Darken, footnote 4). The oxygen curves are calculated with $\Delta H^{\circ}=+66,560$ and $\Delta \mathrm{S}^{\circ}=+20.15$ for the reaction $\mathrm{CO}_{2} \rightarrow 1 / 2 \mathrm{O}_{2}+\mathrm{CO}$.

of the oxidation level (Fig. 2) shown by Muan. ${ }^{5}$ For purposes of the present investigation, which is always concerned with excess silica, the important features of the combined data of Darken's and Muan's works include the following: (a) The lowest melting liquid is at $1150^{\circ} \mathrm{C}$. $\left(2100^{\circ} \mathrm{F}\right.$.) with an iron oxide-to-silica ratio close to the ratio which exists for the binary eutectic, (b) magnetite $\left(\mathrm{Fe}_{3} \mathrm{O}_{4}\right)$ forms as a secondary solid phase when the $\mathrm{CO}_{2} / \mathrm{CO}$ ratio is greater than $10 / 1$,
Table I. Silica-Saturated Liquids (Calculated from Data by Muan, Footnote 5)

\begin{tabular}{ccc}
\hline $\begin{array}{c}\text { Temp. } \\
\left({ }^{\circ} \mathrm{C}\right)\end{array}$ & $\begin{array}{c}\text { Atmosphere } \\
\left(\mathrm{CO}_{2} / \mathrm{CO}_{\text {ratio }}\right)\end{array}$ & $\begin{array}{c}\mathrm{SiO}_{2} \\
\text { (mole fraction) }\end{array}$ \\
\hline 1200 & 1 & 0.43 \\
1200 & 10 & 0.42 \\
1400 & 1 & 0.46 \\
1400 & 10 & 0.45 \\
1500 & 1 & 0.48 \\
1500 & 10 & 0.47 \\
1600 & 10 & 0.5 \\
1600 & Air & 0.4 \\
\hline
\end{tabular}

(c) fayalite $\left(\mathrm{Fe}_{2} \mathrm{SiO}_{4}\right)$ forms as the secondary phase in more reducing environments, and $(d)$ the silica molar composition of the liquid melt is quite insensitive to both temperature and oxidation level. This last feature is summarized in Table $I$.

\section{(3) Microstructural Studies}

Smith $^{6}$ has shown that the microstructures of many materials can be related to the relative interfacial energies as

\footnotetext{
${ }^{5}$ Arnulf Muan, "Phase Equilibria in the System $\mathrm{FeO}-\mathrm{Fe}_{2} \mathrm{O}_{3}$ $\mathrm{SiO}_{2}, " J$. Metals, 7, September 1955; Trans. Am. Inst. Mining Met. Engrs., 203, 965-76 (1955).

- C. S. Smith, "Grains, Phases, and Interfaces: An Interpretation of Microstructure," Metals Technol., 15, No. 4; Trans. Am. Inst. Mining Met. Engrs., 175, 15-51 (1948).
}

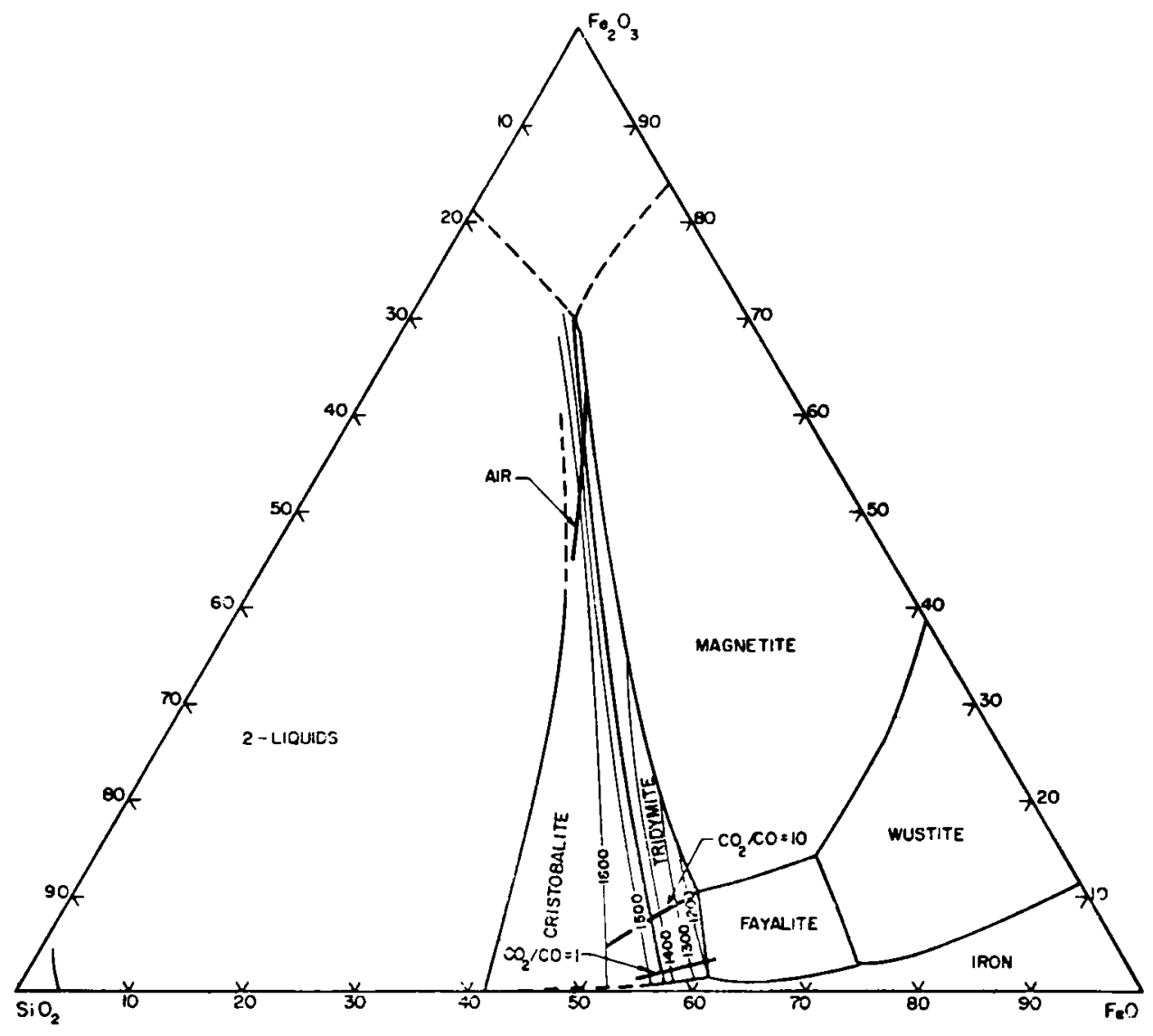

Fig. 2. The system $\mathrm{FeO}-\mathrm{Fe}_{2} \mathrm{O}_{3}-\mathrm{SiO}_{2}$. The oxidation levels are calculated from Muan, footnote 5. 
(B)

(A)
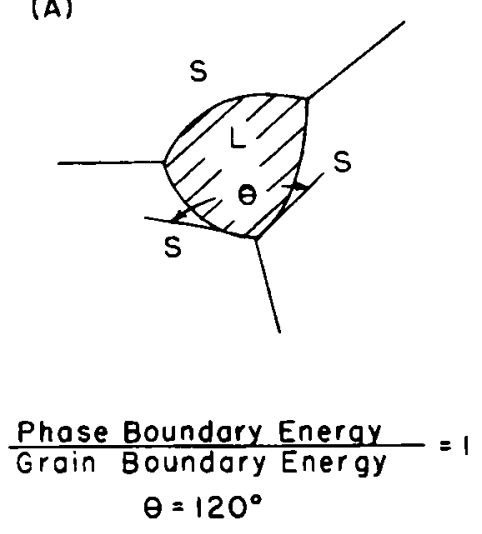

Fig. 3. Phase geometry vs. energy ratios.
(B)

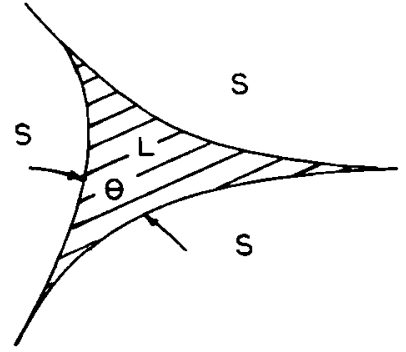

$1>\frac{\text { Phase Boundary Energy }}{\text { Groin Boundary Energy }}>0.5$

$120^{\circ}>\theta>0^{\circ}$

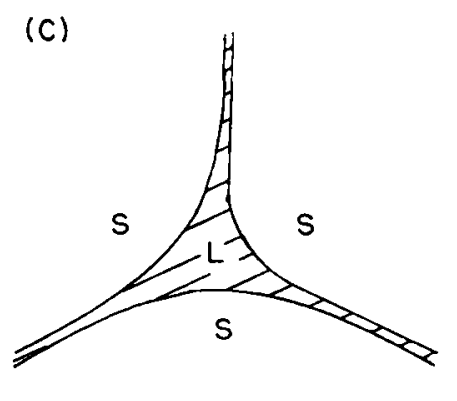

$\frac{\text { Phase Boundary Energy }}{\text { Grain Boundary Energy }} \leqq 0.5$

$\theta=0^{\circ}$ (i.e., continuous film)

The liquids in silica brick approximate the relations shown in (B). The liquids in magnesia brick approximate those in $(C)$. $L=$ liquid; $S=$ solid.

shown in Fig. 3. The dihedral angle, which penetrates between two grains of the same phase, approaches zero as the ratio of the phase-boundary energy to the grain-boundary energy approaches one-half. With lower energy ratios, solid-to-solid grain-boundary contacts disappear.

The actual dihedral angles, which are a function of the relative interfacial energies, cannot be measured directly. Rather, a two-dimensional cut is observed in which the angle may appear to be greater or smaller. However, a statistical sample $e^{6,}$ has a mode which is within $5^{\circ}$ of the true angle $e^{7}$ or a median which is within $1^{\circ}$ of the true angle. ${ }^{8}$

Previous microstructural studies of iron oxide-silica mixtures are limited to phase identifications in the altered zones of silica refractories during service. These data are reported most completely by Harvey. ${ }^{9}$ In general, (1) there is a gray hot-face zone composed of cristobalite and magnetite. (2) The next lower temperature zone contains magnetite and tridymite instead of cristobalite. (3) The following zone has tridymite, less iron oxide, and a large amount of flux rich in $\mathrm{CaO}$ and $\mathrm{Al}_{2} \mathrm{O}_{3}$. The flux may or may not be crystallized. When it does crystallize, calcium and iron metasilicates form from the siliceous liquid. (4) Series of colored bands are usually present between the altered zones and the unaltered brick. This is a staining by vapor deposition and is independent of microstructure.

\section{Experimental Procedure}

Compacts were formed from powders of reagent grades of $\mathrm{SiO}_{2}$ (quartz) and $\mathrm{Fe}_{2} \mathrm{O}_{3}$ and bonded with ethyl silicate which was hydrolyzed with isopropanol to produce an amorphous silicic acid. The initial stages of heating decomposed and volatilized the resulting products except for $\mathrm{SiO}_{2}$ and iron oxide.

Compacts were examined in which $5,10,25$, and $40 \% \mathrm{FeO}$ (added as $\mathrm{Fe}_{2} \mathrm{O}_{3}$ ) were present. The liquid phase of each combination had the same composition but varied in amount (Fig. 2). Since the resulting geometries in the microstructures are identical except for the relative amounts of silica and liquid silicate, most of the quantitative comparisons

\footnotetext{
7 David Harker and E. R. Parker, "Grain Shape and Grain Growth," Trans. Am. Soc. Metals, 34, 156-95 (1945).

8 O. Reigger and L. H. Van Vlack, unpublished data, 1959.

- F. A. Harvey, "Comparison of Used Silica Brick from Insulated and Uninsulated Basic Open-Hearth Roofs," J. Am. Ceram. Soc., 18 [3] 86-94 (1935).
}

were made on the higher iron oxide mixtures which permitted easier microexamination. (The accompanying photomicrographs are of compacts containing $40 \%$ iron oxide.)

The compacts were heated in a combustion tube furnace under $\mathrm{CO}_{2} / \mathrm{CO}$ atmospheres. Three general oxidation levels were chosen: (1) reducing, or $\mathrm{CO}_{2} / \mathrm{CO}=1,(2)$ neutral, or $\mathrm{CO}_{2} / \mathrm{CO}=10$, and (3) oxidizing, or air (see Fig. 1). These oxidation levels may be converted to equivalent oxygen pressures, $P_{\mathrm{O}_{2}}$, by the relation

$$
\log P_{\mathrm{O}_{2}}{ }^{1 / 2}=\log \frac{P_{\mathrm{CO} 2}}{P_{\mathrm{CO}}}-\frac{66,560}{4.575 T}+\frac{20.15}{4.575}
$$

The cooling rate was accentuated by moving the compact from the high-temperature zone to the cold end of the tube furnace. About 1 minute was required to reduce the temperature below red heat. This cooling rate did not produce any evidence of additional silica precipitation. Fayalite or magnetite crystallization was initiated in some but not all the samples. When this occurred, the original silica-liquid interface was not changed, and the high-temperature geometry was preserved. Water quenching was not feasible since it induced cracking and promoted surface oxidation.

Standard micrographic techniques were used for mounting, polishing, and examining reflected-light samples. Quantitative micrographic procedures utilized intersection grids for phase volume measurements by point-count analysis and an ocular micrometer-rotating stage combination for angle measurements. Both of these measurements must be statistical in nature. The point-count-analysis procedure for volume data is based on the fact that the probability that any random point in a sample falls in phase $X$ is equal to the volume fraction of the material which is phase $X$. Of course, the points must be selected in random fashion.

The angular measurements were made from two-dimensional traces of three-dimensional dihedral angles. Figure 4 shows these dihedral angles which developed in a tridymiteliquid microstructure. These angles are essentially independent of the original orientation angle between crystal facrThis fact may be verified experimentally as follows. If all the three-dimensional angles are the same, the statistica distribution will develop among the two-dimensional cuts as shown by the dashed curve in Fig. 5 . If the values of the three-dimensional angles differ, the observed two-dimensional angles do not follow this theoretical distribution, and the distributional mode is less pronounced. ${ }^{8}$ The two sets of data in Fig. 5 contrast the results for equilibrated and nonequilibrated geometric data. 


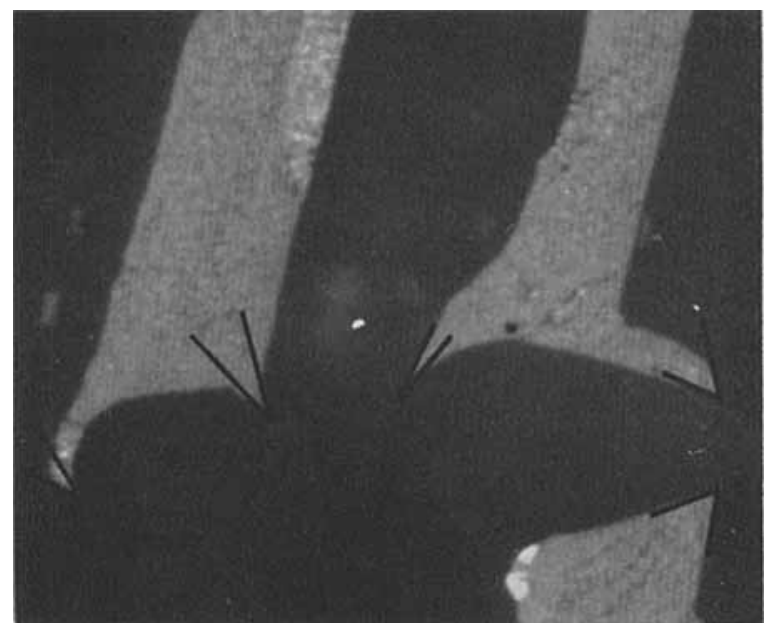

Fig. 4. Dihedral angle measurement lenlarged photomicrograph of Fig. $7(D))$. These angles are two-dimensional traces of threedimensional dihedral faces. The dark area is tridymite and the light areas are the former liquid. (Reflected light; $\times 900$.)

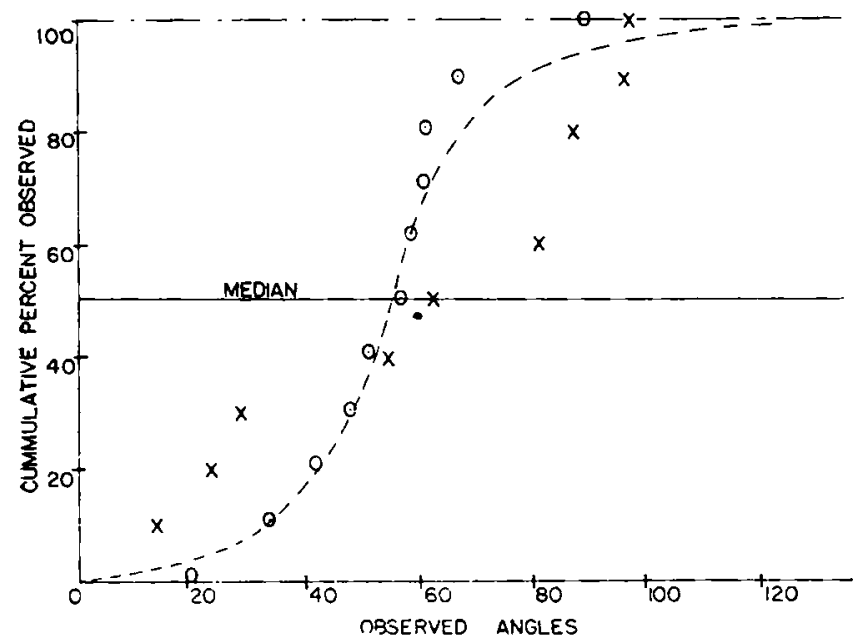

Fig. 5. Statistical distribution of observed dihedral angles. The cumulative distribution matches the normal distribution only when the true angle is constant. (Circles) observed data, 70 hours at $1200^{\circ} \mathrm{C}$. with equilibrated median of $57^{\circ}$; (dashed curvel normal distribution for true angle of $57^{\circ}$; and $(X)$ observed data, 2 hours at $1200^{\circ} \mathrm{C}$., not equilibrated.

\section{Results and Discussion}

General observations include the following facts. (1) The grains of tridymite grew larger than the grains of cristobalite at the same temperature. (2) The cristobalite grains were approximately equiaxed and subhedral. The tridymite grains were initially tabular, presumably basal plates. The planar faces were destroved, however, by prolonged heating. This change started at the grain junctions. (3) Tridymite was never formed above $1470^{\circ} \mathrm{C}$, but cristobalite could be formed below $1470^{\circ} \mathrm{C}$. When cristobalite was formed below $1470^{\circ} \mathrm{C}$, it eventually was replaced by tridymite. (4) Crystal-to-crystal contact was maintained in all samples, even when $40 \%$ iron oxide ( $70 \%$ liquid) was present. As a result the compacts retained their shape during heattreating. These observations are illustrated in Figs. 6,7 , and 8.
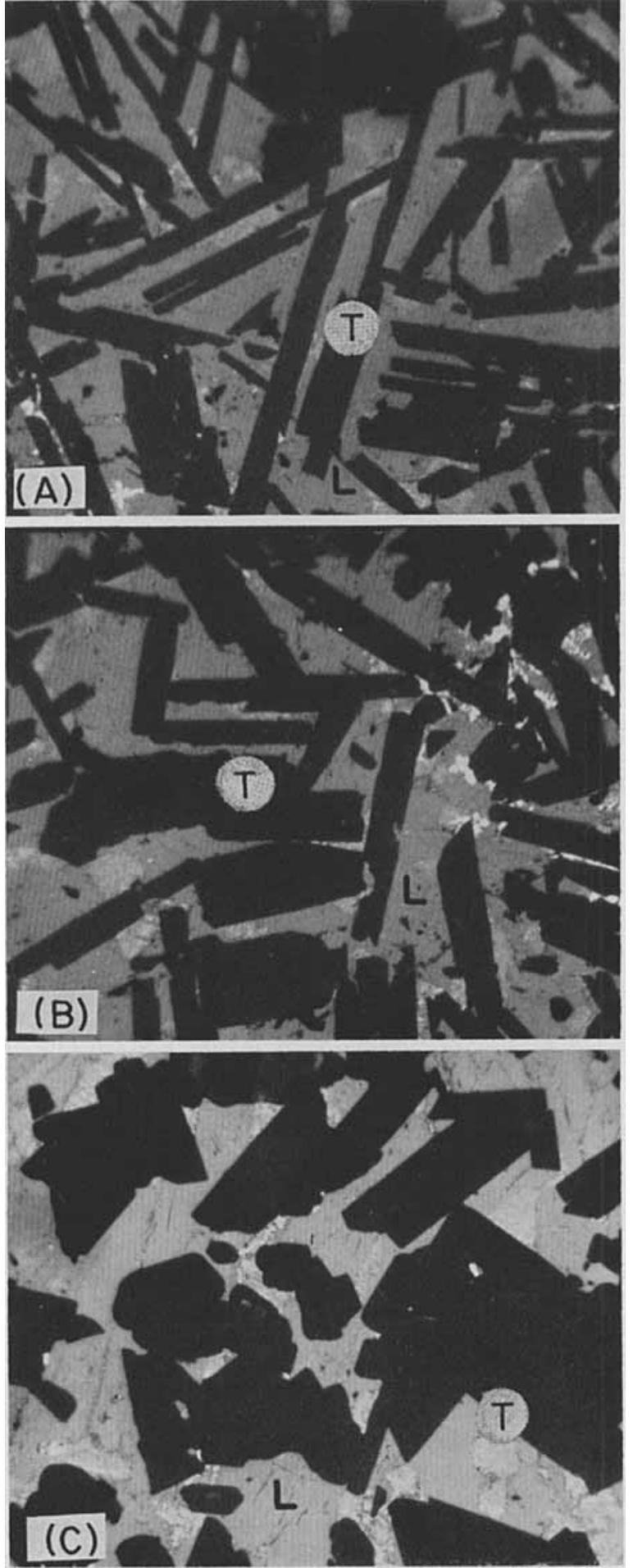

Fig. 6. Tridymite growth in an iron oxide-silica liquid at $1200^{\circ} \mathrm{C}$. $\left(2200^{\circ} \mathrm{F}\right.$.). (A) Two hours with $\mathrm{CO} / \mathrm{CO}=1,(B) 7$ hours with $\mathrm{CO}$ : $/$ $\mathrm{CO}=1$, and $(\mathrm{C}) 70$ hours with $\mathrm{CO}_{2} / \mathrm{CO}=10$. Dark areas are tridymite; light areas were liquid. (Reflected light; $\times 300$.)

\section{(1) Geomeiric Relations}

In an interpretation of the microstructural relations just outlined it must be recognized that cristobalite formed more readily than tridymite but did not continue to grow as rapidly. One explanation which may be advanced is that the cristobalite was nucleated with a lower activation energy. Therefore it might be observed after short heat-treatments both above and below the cristobalite-tridymite equilibrium temperature of $1470^{\circ} \mathrm{C}$. $\left(2678^{\circ} \mathrm{F}\right.$.). In contrast, the tridy- 

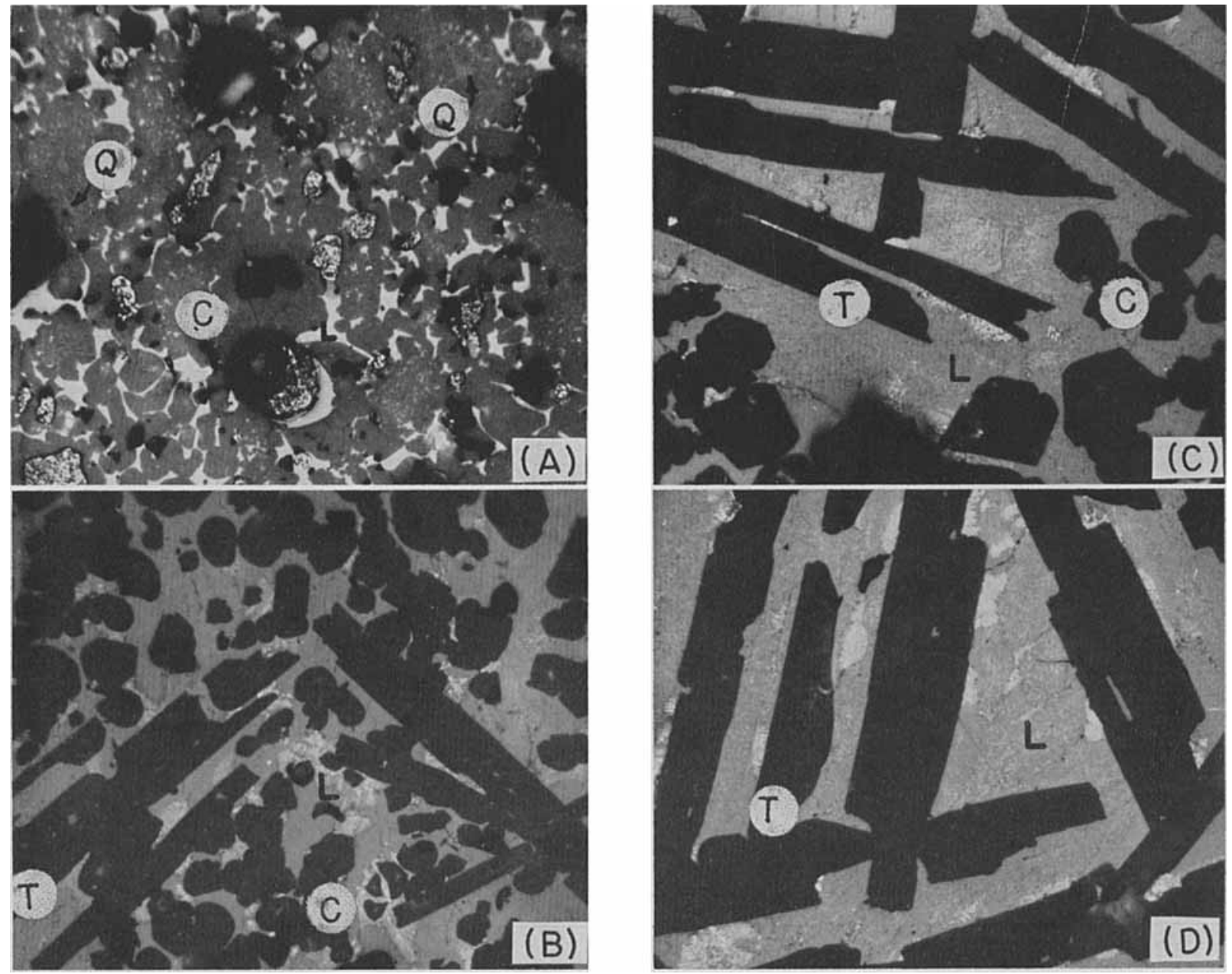

Fig. 7. Silica phase changes in an iron oxide-silica liquid at $1400^{\circ} \mathrm{C}$. $\left(2550^{\circ} \mathrm{F}.\right)$. (A) Thirty minutes with $\mathrm{CO}_{2} / \mathrm{CO}=10$, (B) 2.25 hours with $\mathrm{CO}_{2} / \mathrm{CO}=1$, (C) 7 hours with $\mathrm{CO}_{2} / \mathrm{CO}=1$, and $(\mathrm{D}) 22$ hours with $\mathrm{CO}_{2} / \mathrm{CO}=1$. Remnants of the original quartz may be seen in (A), but most of the solid silica phase already is equiaxed cristobalite. Tridymite is not evident. It grows as basal plates after longer heating times, eventually replacing the cristobalite completely ((B), (C), and (D)). $(\times 300$.

mite, once nucleated, soon exceeded the cristobalite in size (compare the tridymite in Fig. $7(B)$ with the cristobalite in Fig $8(C)$ ). This greater growth rate occurred for tridymite even though it grew at lower temperatures.

With the faster growth rate for the tridymite, there was a more extensive development of external crystal outlines in short-time treatments. Euhedral plates of tridymite were evident in all microscopic observations and were particularly noticeable in the short-time treatments. Apparently the initial rapid growth was controlled by the crystal faces rather than by the minimum interfacial energy for the total structure.

Longer heat-treatments provided an opportunity for the interfacial area to be minimized. Not only was there continued grain growth, but there was also a gradual change of the grain shape from euhedral to subhedral and even anhedral (Fig. $6(C)$ ). Each of the re-entrant angles in such a microstructure occurred at a grain boundary. These dihedral angles approached geometric equilibrium at the grainboundary junction as indicated by the angular distribution ${ }^{8}$ (Fig. 5). Thus, although some crystalline faces still remained, they were gradually being replaced by minimum-area interfaces.

The average tridymite-liquid interfacial energy (Fig. 9) was 0.57 of the tridymite grain-boundary energy at $1200^{\circ} \mathrm{C}$. $\left(2200^{\circ} \mathrm{F}\right.$.). This figure dropped to 0.53 at $1440^{\circ} \mathrm{C} .\left(2625^{\circ} \mathrm{F}\right.$.). The $7 \%$ drop is most readily explained on the basis of a slightly greater solubility of $\mathrm{SiO}_{2}$ in the liquid at the higher temperature. As such the solid and liquid are structurally more similar at the higher temperature while the grain boundary is essentially constant in character.

The cristobalite-liquid mixture behaved similarly to the tridymite-liquid mixture except that the phase-boundary/ grain-boundary energy ratios were about $10 \%$ higher for comparable temperatures (Fig. 9). This difference could involve several possibilities: (1) The energy of the cristobalite-liquid interface was higher than the energy of the tridymite-liquid interface, (2) the cristobalite grain-boundary energy was less than the tridymite grain-boundary energy, or (3) both. The choice of these possibilities cannot be finalized; the second, however, appears to be the most plausible for the following reasons. Planar crystal faces are not involved when geometric equilibrium is developed. Consequently, the average structure of the cristobalite-liquid and the tridymite-liquid interfaces should not be greatly dissimilar. The liquid can unite with either of these solids with approximately the same energy. In contrast, the grain boundaries have solid structures on each side of the boundary. The resulting grain-boundary energy would be expected to be lower for the cristobalite, which has greater internal symmetry than does the tridymite. The energy comparisons reported in Fig. 9 thus are in qualitative agreement with expectations.

Of practical significance is the fact that an increase in temperature did not reduce the dihedral angle to $0^{\circ}$ (i.e., the phase-boundary/grain-boundary energy ratio to $<0.50)$. 


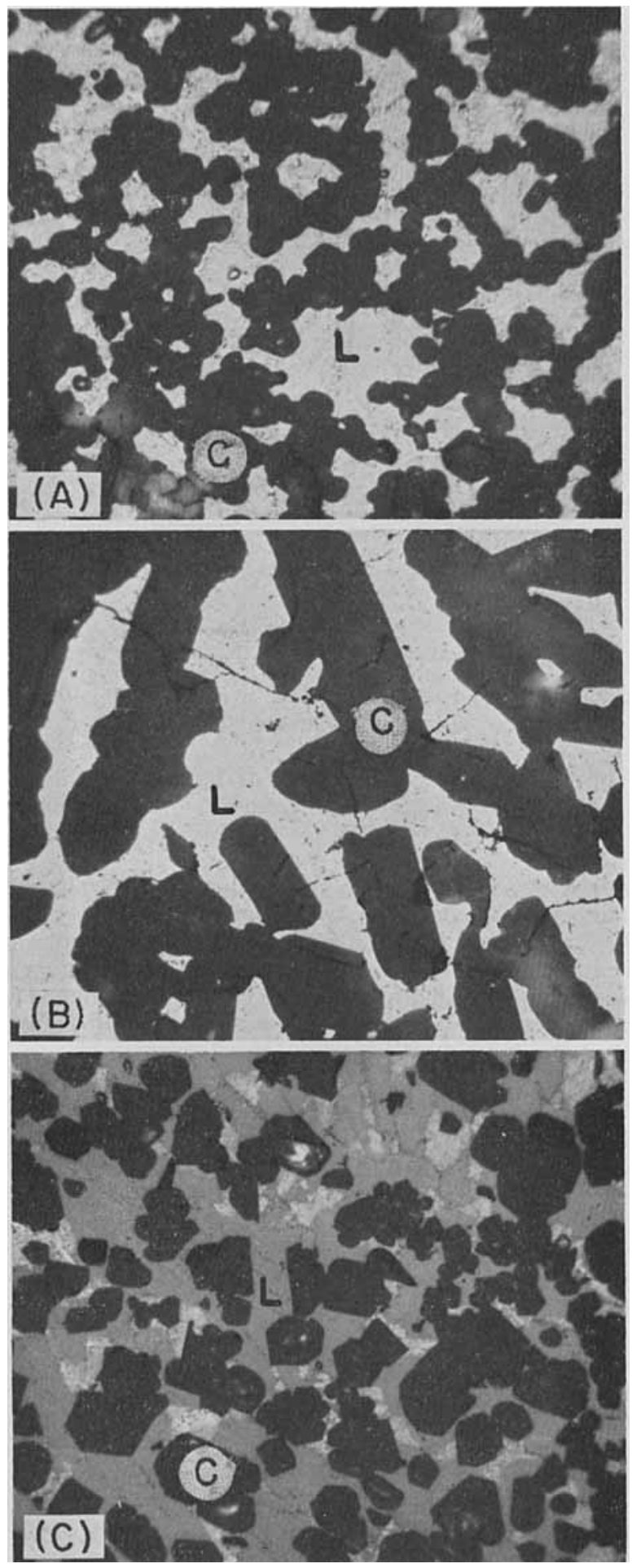

Fig. 8. Cristobalite formation in an iron oxide-silica liquid at $1480^{\circ} \mathrm{C} .\left(2700^{\circ} \mathrm{F}\right.$.). (A) Two hours in air, (B) preheated 18 hours at $2600^{\circ} \mathrm{F}$. and then 2 hours at $2700^{\circ} \mathrm{F}$. in oir, and (C) 2 hours with $\mathrm{CO} / \mathrm{CO}=10$. Each of these samples has similar phaseboundary/grain-boundary energy ratios (see Fig. 9) although their heat-rreating procedures differed. The dark areas are cristobalite and the light areas were liquid. (Reflected light, $\times 300.1$

Although these experiments did not exceed $2800^{\circ} \mathrm{F}$., an extrapolation of the data indicates that $0^{\circ}$ angles would not be reached at the $\mathrm{SiO}_{2}-\mathrm{FeO}$ monotectic temperature. Furthermore, the microstructure of the hot-face zone of silica refractories indicates that the extensive solid-to-solid contact exists $\in$ ven at the melting surface. The solid-to-solid contact which arises from the relative interfacial-energy balances

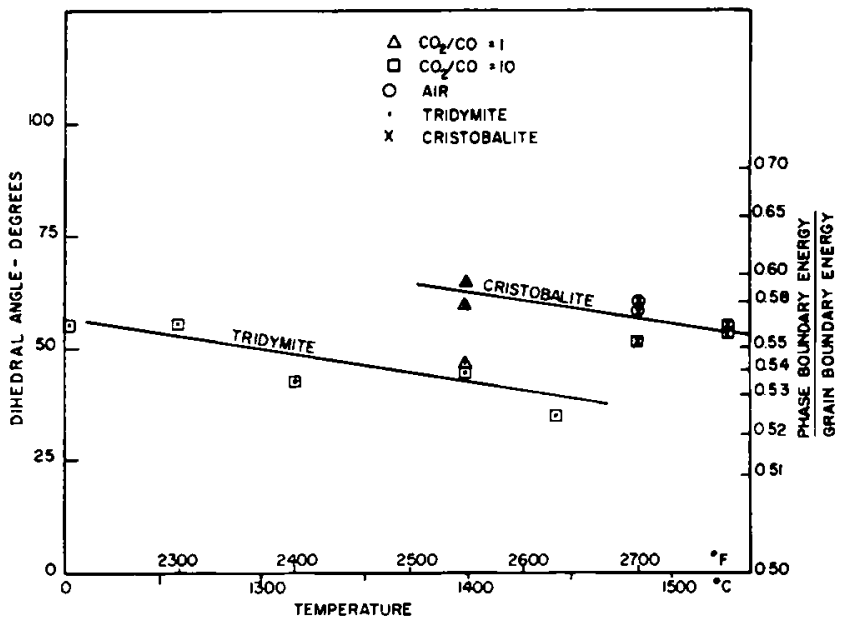

Fig. 9. Dihedral angle vs. temperature.

provides a microscopic skeletal framework. This type of microstructure which does not have a liquid film between the solid grains maintains its strength although the liquid content may be high. The strength is noticed in the laboratory samples which do not slump when as much as $70 \%$ liquid may be present. Likewise, furnace structural stresses may be supported through the solid-to-solid framework with more than $25 \%$ liquid in the refractory.

\section{(2) Oxidation Effects}

More highly oxidizing atmospheres introduced magnetite as a secondary solid phase and decreased the liquid content in accordance with phase equilibrium studies. These atmosphere variations did not affect the liquid-silica boundary energies because no significant variation in the dihedral angles was observed. This absence of effect might be anticipated since a major change in the oxidation level (Table I) changes the liquid only slightly in composition and structure.

The constancy of the dihedral angles with oxidation variations means that a solid silica skeletal microstructure is maintained and that the liquid does not penetrate between the silica grains as it does between the magnesia grains. These observations indicate that the sudden failure of silica refractories in metallurgical furnaces by the impingement of reducing flames arises solely from the resultant increase in the liquid content to abnormally high levels and not from microstructural changes arising from surface-energy requirements.

\section{Conclusions}

The microstructures of silica-iron oxide mixtures will vary with temperature. The oxidizing character of the atmosphere does not have a noticeable effect on the dihedral angles in this particular system. Since the silica molar fraction of the liquid in this system does not vary from approximately 0.45 for various oxidation levels, it may be unwise to generalize that there is an absence of oxidation effects in other systems.

The microstructures of iron oxide-silica mixtures always possess a skeleton of grains with solid-to-solid contact. This provides coherency until abnormally large amounts of liquid are present. It permits the conclusion that silica brick maintain their strength in service because of this microstructural network.

\section{Acknowledgments}

This work was supported in part by a grant (No. 988) from the Faculty Research Fund, Horace H. Rackham School of Graduate Studies, University of Michigan. The help of Tom Altenbern as a student research assistant was indispensable. Ralph $G$. Wells constructively criticized the writer's ideas, and his suggestions are appreciated. 